\title{
HUBUNGAN FREKUENSI MENOTON TV PADA ANAK SD(KELAS V) DENGAN TINGKAT PRESTASI BELAJAR ANAK USIA 10-11 TAHUN
}

\author{
ERNA SUSILOWATI, SITI MUSYAROFAH \\ AKPER DHARMA HUSADA KEDIRI, ernabudi_80@yahoo.co.id
}

\begin{abstract}
Television is feeling important to children. Frequency ang long of watching TV to children's is higher then they are learn frequency. It's means in sociality process they will influenced with TV program's. Objective direction of this scientific work is to know relation between frequency of watching TV to elementary student's ( class V) and learn achievement in child 10-11 years old. Desain that we using is correlation with cross sectional metode. The sample in elementary student's class V in SDN Drenges II kertosono. Total sampling 13 student's. We use systemic observation to gathering data and analys with pearson's coefisien correlation and interval correlation value. Result that we get in scientific work is $r: 0,1$, that's mean frequency of watcing TV and leanring achivment have positif relatioan and the table of coefisien correlation $0,00<\mathrm{KK}<=0,20$ having weak relation. We can say that frequency of watching TV and learn achivment hava relation., but many another factor can be influenced children achivment. Like children's IQ, environment and learning tool's. so we must can be arrange of time to children to learn and play. Paretnt's role is too important for supporting chid.
\end{abstract}

\section{Key's word: Television, learn achivment, children}

\section{PENDAHULUAN}

Teknologi semakin canggih dan intensitasnya semakin tinggi. Anak lebih banyak menghabiskan waktu menonton TV dari pada melakukan hal lainnya, hal ini menjauhkan mereka dari pelajaranpelajaran hidup yang paling penting seperti bagaimana cara berinteraksi dengan teman seabayanya, belajar cara berkompromi dan berbagi dunia yang penuh dengan orang lain serta berpengaruh terhadap perkembangan otaknya. Anak merupakan kelompok pemirsa yang paling rawan dengan dampak negatif siaran TV. Selain mempengaruhi perkembangan otak, berpengaruh terhadap sikap, mengurangi semangat belajar, membentuk pola pikir sederhana, mengurangi konsentrasi, mengurangi kreativitas, meningkatkan obesitas karena saat menoton TV aktifitas sangat berkurang sedangkan asupan makanan tetap bahkan bertambah sehingga terjadi ketidakseimbangan antara asupan energi dengan keluaran energi, selain itu juga dapat merenggangkan hubungan antar keluarga dan matang secara seksual lebih cepat. ( Daniel Mahendra,2009)

Bahkan "kidia" mencatat bahwa pada tahun 2004 acara untuk anak yang aman hanya sekitar $15 \%$ saja. Saat ini jumlah acara TV yang di tayangkan untuk anak usia Sekolah Dasar (SD) perminggu sekitar 80 judul dalam 300 kali penayangan selama 170 jam, padahal dalam seminggu ada 168 jam. Jadi, sangat berlebihan. Hasil penelitian pada tahun 2006 mengenai jumlah jam menonton TV pada anak di Jakarta Bandung yang mendapati angka sekitar 30-35 jam seminggu atau 4,5 jam sehari sehingga dalam setahun kurang lebih 1600 jam. Sementara jumlah jam sekolah sekitar 5 jam/hari untuk kelas 4 sampai kelas 6 dan 3 jam/hari intuk kelas 1 sampai kelas 3 . Jadi rata-rata jam sekolah 740 jam setahun. (kidia, 2009)

Masalah yang perlu mendapat perhatian bukan hanya berapa lama anak menonton TV, lebih dari itu yang perlu di perhatikan adalah acara apa saja yang di gemari dan sering di tonton anak-anak 
serta mempengaruhi hidup mereka. (Marsaja, 2009).

Film kartun, sinetron dan acara anak seperti telekuis anak menjadi pilihan anak dalam meonton TV di bandingkan berita ataupun tayangan edukativ seperti film documentary mengenai hewan atau yang lainnya. Jika anak tidak menonton TV dalam 1 hari, ia akan merasa resah, gelisah seperti ada sesuatu yang kurang dalam menjalani kegiatan di hari itu (Taufiqqurahman, 2010). Frekuensi menoton TV pada anak-anak jauh lebih tinggi di banding frekuensi mereka belajar. Itu berarti dalam proses sosialisasi anak akan lebih besar di pengaruhi siaran TV. Dengan beberapa dampak buruk ini kita harus berusaha agar anak -anak tidak tumbuh menjadi generasi televisi. (Irkham Agus, 2009).

Disadari atau tidak televisi sebagai produk teknologi dan budaya yang telah menjadi media komunikasi yang harus di akui sangat efektif dan efisien artinya televisi juga bisa menjadi alternatif pilihan media pembelajaran anak/siswa. Berikut saran yang di berikan oleh Elly Risman, Psi mengenai tontonan TV pada anak: batasi maksimal 2 jam, seleksi program (Tidak semua program layak di tonton anak), biasakan meminta ijin sebelum menonton TV, minta dukungan lingkungan, dampingi anak (jelaskan hal positif dan negatif yang di lihat anak dari televisi). ( yayasan kita dan buah hati, kidia 2009)

Prestasi belajar dapat di tingkatkan dengan mudah bila kita dapat membantu anak menyingkirkan tiga penghambat utama proses belajar, yaitu penghambat kritis-logis (anak merasa bersekolah itu sulit dan tidak menyenangkan), penghambat intitusif - emosional ( anak merasa dirinya bodoh) dan penghambat kritis- moral ( anak merasa belajar merupakan kegiatan yang membutuhkan banyak upaya keras dan anak tidak mampu). (Georgy lozanov, Bapak accelerated learning dunia). Dengan memahami permasalahan utama pada anak di harapkan orang tua dan guru perlu membangun kesadaran anak dan tanamkanlah pada anak agar memiliki persepsi yang menarik bahwa pembelajaran adalah proses yang mengasyikan. (Marsaja, 2009)

\section{METODE PENELITIAN}

Dalam penelitian ini desain penelitian yang di gunakan adalah korelasi dengan menggunakan metode pendekatan cross sectional yaitu suatu penelitian untuk mempelajari dinamika korelasi anatar faktor-faktor resiko dan efek dengan cara pendekatan atau pengumpulan data sekaligus pada suatu saat. ( Notoadmodjo, 2005: 145-146). Dalam penelitian ini, peneliti mencoba mencari hubungan frekuensi menonton TV pada anak SD (kelas V) dengan tingkat prestasi belajar anak usi (10-11 th) di SDN Drenges II kecamatan Kertosono

Teknik sampling dalam penelitian ini adalah total sampling yaitu cara pengambilan anggota semua menjadi sampel. (H.A.Alimul Aziz,2008)

Terdapar 13 responden untuk penelitian ini dari siswa kelas V SDN Drenges II Kecamatan Kertosono. Dalam penelitian ini yang menjadi variabel independent adalah frekuensi menonton TV pada anak SD kelas V. Dalam penelitian ini yang menjadi variabel dependent adalah tingkat prestasi belajar anak usia 10-11 th

Dari hasil data penelitian yang di dapatkan dari semua responden kemudian di analisa menggunakan rumus koefisien korelasi pearson 


\section{HASIL PENELITIAN}

1. Frekuensi menonton TV pada anak

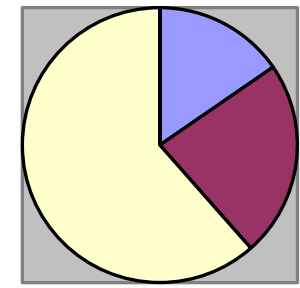

口Tidak Sehat
Membahayak
an

Gambar 1. Frekuensi menonton TV pada anak SD kelas V SDN Drenges II

Gambar di atas menunjukkan bahwa lebih dari sebagian $(61,5 \%)$ memiliki kebiasaan menonton TV yang berlebihan, dan sebagian kecil $(23,1 \%)$ memiliki kebiasaan lama menonton TV dalam kategori membahayakan dan sebagian kecil lagi $(15,4 \%)$ dalam kategori tidak sehat yaitu sekitar 11-15 jam /minggu

2) Tingkat prestasi belajar anak
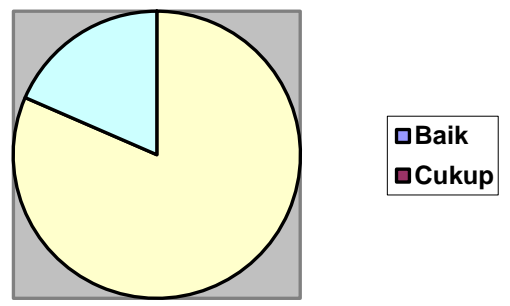

Gambar 2 Prosentase prestasi belajar anak SD kelas V di SDN Drenges II

Berdasarkan gambar di atas sebagian kecil $(7,7 \%)$ dari siswa memiliki prestasi belajar yang baik (76-100) dan ini hanya 1 responden. Sedangkan mayoritas responden $(92,3 \%)$ dari responden memiliki prestasi belajar yang cukup (5675) untuk prestasi belajar

Pada perhitungan koefisien korelasi pearson mendapat nilai r: 0,1 memberikan arti bahwa frekuensi menonton TV dengan tingkat prestasi belajar yang di capai terdapat hubungan positif dan menirut tabel koefisien korelasi di ketahui bahwa nilai $0,00<=\mathrm{KK},=0,20$ memiliki kekuatan hubungan yang sangat rendah atau lemah sekali

\section{PEMBAHASAN}

\section{Frekuensi menonton TV Pada Anak}

Berdasarkan gambar 1 di ketahui dari sebagian $(61,5 \%)$ responden memiliki kebiasaasn menonton TV antara 16-27 jam/minggu yang merupakan kategori melebihi dalam arti jumlah atau frekuensi menonton TV yang berlebihan. Pada gambar 1 di dapat juga sebagian kecil $(15,4 \%)$ responden menonton TV antara 11-15 jam/minggu dan sebagian kecil $(23,1 \%)$ responden dalam penelitian memiliki kebiasaan menonton $\mathrm{TV}>28$ jam/minggu.

Sesuai teori yang di ungkapkan oleh chen dalam bukunya yang berjudul "the parent Guide ti Kids TV", chen menunjukkan waktu menonton TV yang cukup sehat adalah berkisar 8-10 jam/minggu dengan kata lain, lamanya waktu menonton TV sebaiknya berada pada rentang 1 jam 9 menit sampai 1 jam 25 menit, dan batas waktu maksimal menonton adalah 15 jam seminggu dan itu sudah termasuk kategori tidak sehat. (Irkham Agus, 2009)

Dari data yang di peroleh tersebut petut kita cermati, akibat menonton TV dalam jumlah waktu yang lama/tidak proporsional dari tayangan TV akan dapat menimbulkan pikiran yang lazim pada anak bahwa apa yang terjadi di TV adalah sesuatu yang wajar, normal, norma

Standart, biasa terjadi di kehidupan sekitar kita. Bearangkat dari pengertian yang demikian timbulah peniruan sekaligus identifikasi akibat imitasi dalam waktu yang lama. Hasilnya anak-anak lebih impulsif (menurutkan) apa yang di inginkan menjadi tak terkendali. Mencoba menirukan, mempraktikan apa yang di lihat dan di dengar serta di pertontonkan di TV. Menyadari semua itu, kita boleh merasa khawatir, terutama orang tua. Karena anak-anak akan tumbuh dan menjadi genersi televisi yaitu mereka yang menonton tayangan program televisi sebagai bagian yang tidak mungkin di 
pisahkan dari kehidupan sehari-hari. Dengan TV dalam keadaan mati, anak jadi memiliki kesempatan untuk berpikir. Membaca, berkreasi dan melakukan sesuatu. Untuk menjalin hubungan yang lebih menyenangkan dalam keluarga dan masyarakat. Mengurangi waktu menonton TV membuat anak lebih banyak waku untuk bermain di luar, berjalan-jalan atau melakukan olah raga yang di senangi. Perkenalkan anak bahwa televisi di gunakan untuk sarana pendidikan seperti televisi memperluas dan membuka cakrawala. Televisi adalah ibarat jendela dunia di mana kita dapat menengok segala sesuatu di luar sana, memperkaya pengalaman hidup. Televisi juga memungkinkan kita mengalami berbagai hal tanpa harus merasakannya sendiri dan menyediakan sarana hiburan murah dan meriah untuk membunuh kejenuhan dan kebosanan kita. Jadi, tetap ajari anak untuk bisa membagi waktu untuk menonton TV dan melakukan banyak hal yang lainnya. Untuk tetap dapat mengembangkan kreatifitasnya terutama sosialnya.

\section{Tingkat Prestasi Belajar Anak}

Berdasarkan gambar 2 prestasi belajar anak usia 10-11 tahun kelas V, menunjukkan mayoritas $(92,3 \%)$ memiliki penilaian cukup (56-75). Juga di dapatkan sebagian kecil $(7,7 \%)$ memiliki nilai baik (76-100). Sesuai teori yang di ungkapkan oleh marsaja bahwa salah satu faktor yang menunjang keberhasilan belajar adalah tersedianaya alat Bantu belajar serta bahan baku penunjang, salain usaha dari anak itu sendiri. Dukungan baik secara materi seperi buku, juga di perlukan dukungan dari keluarga karena sebagian besar waktu belajar di laksanakan di rumah. Perkembangan intelektual juga di poengaruhi oleh beberapa faktor seperti kesehatan gizi, kebugaran jasmani., pergaualan dan pembinaan orang tua. (Marsaja,2009).

Dari data yang di peroleh kita harus memahami terlebih dahulu bahwa setiap aktifitas yang di lakukan seseorang tentu ada faktor yang mempengaruhinya, baik yang cenderung mendorong ataupun yang menghambat. Demikian juga belajar bisa di pengaruhi oleh Intelegensi, minat siswa dan keadaan fisik serta lingkungan dari luar diri siswa seperti guru dan sumber belajar. Selain itu pahami juga permasalahan utama yang biasa terjadi pada anak seperti bahwa bersekolah itu adalah sulit, anak merasa dirinya bodoh dan tidak mampu balajar dan anak merasa belajar merupakan kegiatan yang membutuhkan upaya keras sehingga anak merasa tidak mampu. Dari sini di harapkan orang tua dan guru perlu membangun kesadaran anak. Sehingga anak tidak akan mempunyai persepsi yang buruk tentang sekolah. Jangan sampai anak berpandangan bahwa sekolah adalah pekerjaan yang membosankan dan memberatkan. Tanamkanlah pada anak agar memiliki persepsi yang menarik bahwa pembelajaran adalah proses yang mengasyikan dan menarik, dapat mengatahui hal-hal baru, belajar akan menambah pengalaman baru. Dengan mengubah persepsi anak di harapkan akan memperingan langkah orang tua dan guru agar anak dapat belajar sebagaimana belajar untuk kemanfaatan dia kembali bukan orang lain. Dengan persepsi positif di harapkan orang tua, guru dan masyarakat dapat bersama-sama membantu proses pembelajaran anak sehingga mereka dapat memanfaatkan umurnya untuk menyerap ilmu sebanyakbayaknya dan kelak dapat di praktekan dalam kehidupan sehari-hari

\section{Hubungan Frekuensi MenontonTV pada Anak SD (kelas V) dengan tingkat Prestasi Belajar Anak Usia 10-11 tahun}

Dari hasil penelitian di dapatkan koefisien korelasi pearson mendapat nilai 0,1 yang memiliki arti bahwa frekuensi menoton TV dan tingkat prestasi belajar memiliki hubungan positif dan menurut tabel koefisien korelasi $0,00<\mathrm{KK}<=0,20$ 
memiliki kekuatan hubungan yang sangat lemah atau rendah. Sesusaai teori Georgy lozanov yang menyatakan bahwa ada banyak faktor yang dapat mempengaruhi seperti faktor yang berasal dari dalam diri siswa sendiri yaitu faktor intelegensi, faktor minat dan keadaan fisik serta psikis siswa. Faktor dari luar diri siswa seperti faktor guru, faktor lingkungan keluarga dan faktor sumber belajar. Faktor-faktor tersebut saling mempengaruhi satu sama lain untuk mendapat keberhasilan siswa itu sendiri.

Dari data di atas kita dapat mengetahui bahwa dampak negatif siaran televisi tidak hanya mengenai prestasi belajar, selain menyita banyak waktu, banyak mempengaruhi perbuatan anak seperti perbuatan kekerasan dan anti sosial. Tidak di ragukan lagi banyak adegan semacam ini di pertontonkan di TV. Sadar atau tidak manusia adalah makhluk yang cenderung untuk menjadi peniru ( Irkham Agus, 2009). Sebuah penelitian juga menunjukkan bahwa aktifitas anak cenderung menurun ketika anak tersebut labih memilih aktifitas di dalam rumah dari pada melakukan aktivitas di luar rumah seperti berenang, berolah raga, jalan-jalan, dll. Untuk itu akan lebih baik mengajarkan anak untuk disiplin waktu sejak dini ( Lozanov, 2008). Dimana mereka di ajarkan untuk dapat mengatur waktu untuk bermain dan belajar serta pembatasan waktu untuk menonton TV dan ajarkan juga bahwa bersosialisasi dengan orang lain dan lebih mengenal alam akan sangat bermanfaat bagi mereka. Prestasi belajar anak pun dapat di tingkatkan dengan mudah jika anak memiliki persepsi yang menarik tentang belajar dan mengerti manfaat belajar untuk mereka. Oleh karenanya, dukungan dari oarng tua sangat di butuhkan oleh anak (Lozanov,2008)

\section{KESIMPULAN}

1. Frekuensi menoton TV pada anak SD kelas V di SDN Drenges II kecamatan kertosono lebih dari sebagian memiliki kebiasaan menonton TV berlebihan. Ini memperlihatkan bahwa sebagian besar anak sekarang lebih banyak menghabiskan waktu menonton TV di bandingkan jam belajar mereka yang dapat mempengaruhi prestasi belajar mereka

2. Tingkat prestasi belajar anak SD kelas $\mathrm{V}$ di SDN Drenges II mayoritas menunjukkan prestasi belajar yang cukup. Di mana untuk mendapatkan prestasi belajar yang baik selain dari dasar keinginanya sendiri anak juga bisa di pengaruhi faktor-faktor dari luar dirinya seoperti lingkungannya.

3. Hasil analisa hubungan frekuensi menonton TV pada anak SD kelas V di SDN Drenges II mendapatkan hubungan yang positif tetapi sangat lemah ataun rendah antara frekuensi menonton TV dengan tingkat prestasi belajar anak usia 10-11 tahun yang memiliki arti bahwa frekuensi menoton TV juga mempengaruhi prestasi belajar anak tetapi faktor dari luar atau dari dalam diri siswa juga turut mendukung keberhasilan diri siswa

\section{Saran}

Dari kesimpulan di atas peneliti dapat memberikan saran sebagai berikut:

1. Keluarga memilih tontonan yang edukatif untuk perkembangan kognitif anak

2. Tenaga kesehatan dan guru menjelaskan tips agar TV aman bagi mata dan telinga:

\section{DAFTAR PUSTAKA}

Arikunto, Prof.Dr.Suharsini, 2010. ProsedurPenelitian (pendekatan praktek. Jakarta: Rineka cipta

Ensiklopedia bebas. 2009. Televisi. (Http:// wikipedia. Org/ dioakses 5 januari 2009 (14.30))

Ensiklopedia bebas. 2009. Frekuensi (Http:// wikipedia. Org/ dioakses 6 pebruari 2009 (17.30)) 
Lozanov, georgi. 2008. Prestasi belajar.

(Http://www. Marsaj. wordpress.

Org/ dioakses 16 januari 2009

(16.45))

Hasan iqbal. 2009 Analisis data penelitian dengan statistic. Jakarta:bumi aksara

Irkham, agus. M. 2009. Anak-anak generasi televisi. (Http:// www.suara merdeka .com/ diakses 7 januari 2009 (16.00))

Mahenra, Daniel. 2009. anak dan televisi. (Http:// Daniel mahendra.com diakses 5 januari 2009 (14.50))

Marsaja. 2009. cara peningkatan prestasi belajar anak (Http:// marsaja. Wordpress diakses 16 pebruari 2009 (14.50))

Muscary, mary.E. 2005 Panduan belajar : Keperawatan pediatrik. Jakarta :EGC

Negoro, adi. 2008. Pengertian prestasi belajar(Http:// sobat baru.blogspot diakses 5 januari 2009 (12.36))

Nursalam.2008. konsep dan penerapan metodologi penelitian ilmu keperawatan : pedoman skripsi, testis dan instrument penelitian keperawatan . Jakarta salemba

Nursalam.2008. konsep dan penerapan metodologi penelitian ilmu keperawatan : pedoman skripsi, testis dan instrument penelitian keperawatan . Jakarta salemba

Sugiono, Prof.Dr.2009. Statistika untuk penelitian. Badung: $\mathrm{CV}$ : Alfabeta

Sugiono, Prof.Dr.2010.Metode Penelitian Non ParametriksBadung:CV: Alfabeta 